\title{
Hydrogenation of cinnamaldehyde with heterogeneous catalyst in the presence of cyclodextrins
}

\author{
Mohamad Jahjah,, ${ }^{\text {a,b }}$ Benoit Caron,, ,a Stéphane Menuel,,,d Eric Monflier,, c,d, Laurent \\ Djakovitch $^{\mathrm{a}, \mathrm{b}}$ and Catherine Pinel ${ }^{\mathrm{a}, \mathrm{b}}$ \\ ${ }^{a}$ Univiversité de Lyon, F-69622, Lyon, France \\ ${ }^{b}$ Institut de Recherches sur la Catalyse et l'Environnement de Lyon; CNRS-Université Lyon1; \\ UMR 5256, 2 avenue Albert Einstein, F-69626 Villeurbanne, France \\ ${ }^{c}$ Université Lille Nord de France, F-59000 Lille, France. \\ ${ }^{d}$ U Artois, UMR 8181, UCCS, Faculté des Sciences Jean Perrin, Rue Jean Souvraz, SP 18 - \\ 62307 Lens cedex, France \\ E-mail: eric.monflier@univ-artois.fr
}

\section{Dedicated to Professors Rita H. Rossi, Julio C. Podestá, Manuel González Sierra and Oscar S. Giordano}

DOI: $\underline{\text { http://dx.doi.org/10.3998/ark.5550190.0012.733 }}$

\begin{abstract}
Hydrogenation of cinnamaldehyde in water in the presence of cyclodextrin and supported metallic catalyst has been investigated. The nature of the metal plays the main role in the selectivity of the reaction. The formation of allylic alcohol was achieved in the presence of $\mathrm{Pt} / \mathrm{C}$ and was slightly improved after addition of cyclodextrin substituted with triazole moiety. However, the contribution of cyclodextrin is modest due to the partial solubility of cinnamaldehyde in water.
\end{abstract}

Keywords: Hydrogenation, cinnamaldehyde, allylic alcohol, cyclodextrin, heterogeneous catalysts

\section{Introduction}

The selective hydrogenation of $\alpha, \beta$-unsaturated aldehydes is of great importance as well for industrial applications and comprehensive aspects. ${ }^{1}$ The corresponding unsaturated alcohols found applications in fine chemistry as intermediates in flavour, fragrance or pharmaceutical. ${ }^{2}$ As the $\mathrm{C}=\mathrm{C}$ bond is thermodynamically more easily hydrogenated than the $\mathrm{C}=\mathrm{O}$ bond, the selective 
metal catalyzed hydrogenation of conjugated aldehyde to the corresponding unsaturated alcohol remains a challenge.

To circumvent this difficulty several metal hydrides (LiAlH4, NaBH4...) were used in the past to reduce selectively the considered substrate to allylic alcohols. However, they are used in stoichiometric amounts producing therefore large quantity of salts. As solutions, alternative catalytic hydrogenations were reported. For example, homogeneous $\mathrm{Rh}$, Ir and Ru-complexes are efficient and selective using either hydrogen or HCOONa as reductant. ${ }^{3}$ These catalysts were used as well in organic solvents or water. To improve catalysts separation, several heterogeneous catalysts were developed. While very efficient, they still suffer of lower selectivity. As a general rule, iridium and osmium catalysts exhibit moderate efficiency in the hydrogenation of $\alpha, \beta$ unsaturated aldehyde whereas yielded allylic alcohol in high selectivity. On the other hand, high activity, but low selectivity, was achieved with nickel and palladium catalysts. To end, using platinum or ruthenium catalysts intermediate activity and selectivity was observed. ${ }^{4}$

In order to develop suitable catalysts, extensive efforts have been made. Beside the modification of a platinum group metal catalyst by doping with second metal, ${ }^{5}$ the main developments concerned the nature of the support that was found to play a role in the selectivity of this reaction. While carbon and non porous metal oxides were mainly investigated, zeolite, clays or carbon nanotubes were also evaluated. ${ }^{6}$ Interestingly, it was shown that enhanced selectivity could be achieved thanks to steric effect either due to mutual constraints between the metal surface and the molecule (related to the particle sizes) or, using zeolite as support for metals, imposed adsorption of the aldehyde moiety onto the metal particle resulted from a kind of restricted transition state due to cage effect in zeolite. ${ }^{7}$ More recently, catalyst prepared from carbon nanotubes as support allowed also increasing selectivity toward the corresponding allylic alcohol thanks to the preparation of metal particles with the adequate size as well as modifications in the surface chemistry of the catalyst achieved by catalyst's post-reduction treatment. ${ }^{8}$

Most of the time, organic solvents were used for this transformation but to develop a more environmentally friendly step, the use of water as solvent is highly desirable. If this approach was developed with soluble metal complexes, to our knowledge, no literature described it with supported metal catalysts. One of the drawbacks relies on the insolubility of the substrate in water. This problem could be circumvented by performing the hydrogenation in the presence of cyclodextrins (CDs). Indeed, these additives are well known to play a positive role in a large number of reactions in aqueous media. ${ }^{9}$ In fact, CDs can form inclusion complexes with hydrophobic substrates and solubilise them in aqueous medium. Additionally, it was found that CDs can interact with heterogeneous catalysts by adsorbing at the surface favouring thus their dispersion in aqueous phase by increasing the hydrophilic character of the support. ${ }^{10}$

In this contribution we report the results achieved in the selective hydrogenation of cinnamaldehyde using supported monometallic catalysts in water with the objective of establishing the influence of adding cyclodextrins (Figure 1). 

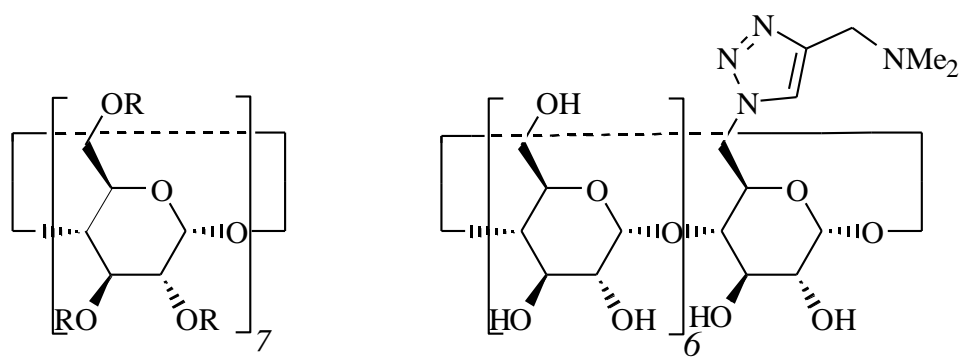

B-CD: $\mathrm{R}=\mathrm{H}$

RAME- $\beta-C D: \mathrm{R}=\mathrm{H}$ or $\mathrm{CH}_{3} ; \mathrm{DS}=1.7$

T- $\beta-C D$

HP- $\beta$-CD: $\mathrm{R}=\mathrm{H}$ or $\mathrm{CH}_{2} \mathrm{CHOHCH}_{3} ; \mathrm{DS}=0.6$

Figure 1. Cyclodextrins used in the study.

\section{Results and discussion}

The catalytic performance of commercial $\mathrm{Pd} / \mathrm{C}$ catalyst was evaluated in the hydrogenation of cinnamaldehyde (CAL) in $\mathrm{MeOH}$ and aqueous phase (Scheme 1).

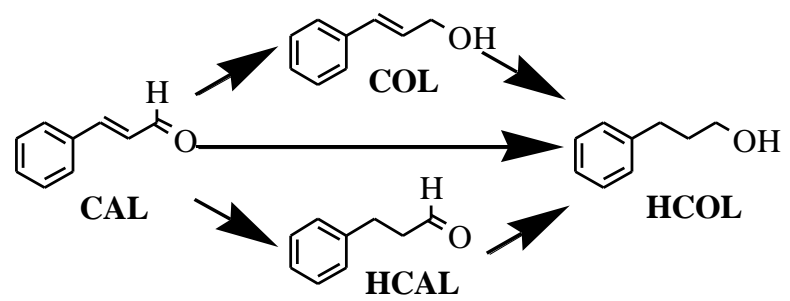

Scheme 1. Reaction pathways in the hydrogenation of cinnamaldehyde.

The reaction was carried out under 1 atm $\mathrm{H}_{2}$ at room temperature. The results obtained in both solvents are reported in Figure 2. It is clear that the nature of the solvent played a significant role on the reaction rate: while in $\mathrm{MeOH}$, complete conversion was achieved after $2 \mathrm{~h}$, only $68 \%$ conversion was obtained after $6 \mathrm{~h}$ in water. This can be attributed to the low solubility of cinnamaldehyde in water $(1.4 \mathrm{~g} / \mathrm{l})$. 


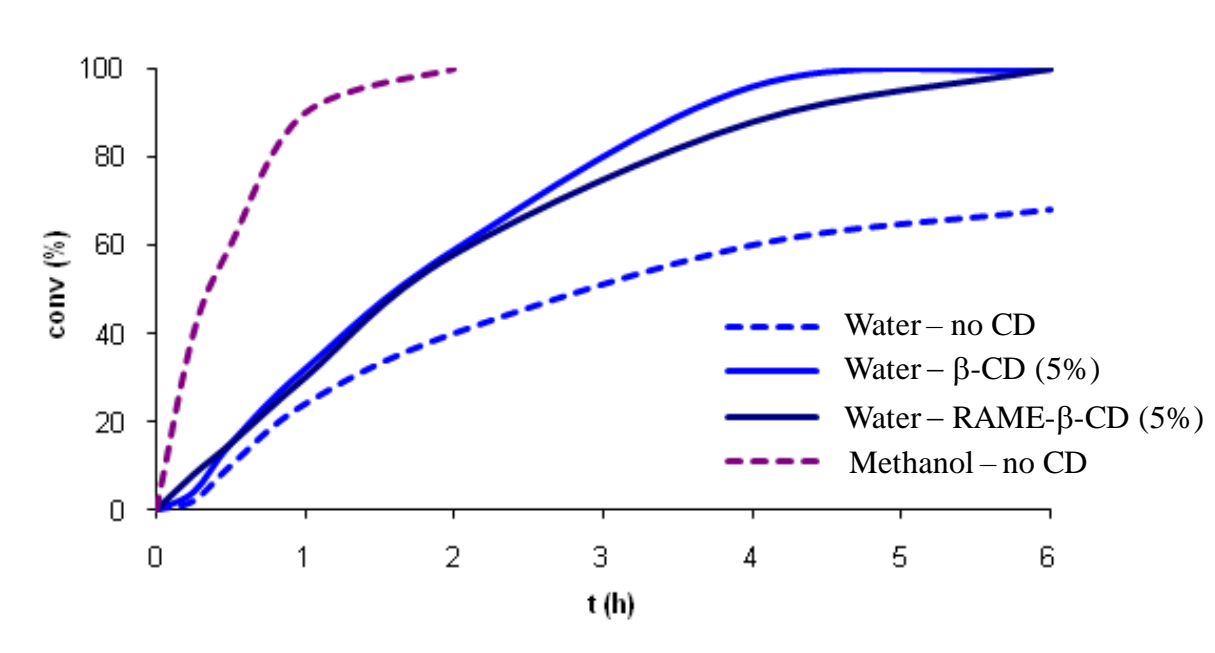

Figure 2. Hydrogenation of cinnamaldehyde in the presence of $\mathrm{Pd} / \mathrm{C}$. Reaction conditions: cinnamaldehyde $(150 \mathrm{mg}), \mathrm{H}_{2} \mathrm{O}(10 \mathrm{~mL}), \mathrm{Pd} / \mathrm{C}(1 \%)$, room temperature, when mentioned $\beta$-CD (65 mg), RAME- $\beta$-CD (75 mg).

Effect of native $\beta-\mathrm{CD}$ and randomly methylated $\beta-\mathrm{CD}$ (RAME- $\beta-\mathrm{CD})$ was then evaluated. The cyclodextrins were added at a $5 \%$ molar ratio in respect to cinnamaldehyde. Irrespective to the nature of the cyclodextrins, the performances of the catalytic system increased significantly and complete conversions were achieved after $5 \mathrm{~h}$.

The benefit effect of cyclodextrins on conversion is likely a consequence of a combination of two effects: the well-known mass transfer promoter properties of the CDs and their dispersing role on the $\mathrm{Pd} / \mathrm{C}$ catalyst. Benefit effect of cyclodextrin on mass transfer has been ascribed to the formation of inclusion complex between the aromatic ring of cinnamaldehyde and cyclodextrin increasing the solubilization of the substrate in water. The interaction between cinnamaldehyde and cyclodextrin was studied in aqueous solution by numerous research groups. ${ }^{11-13}$ These works have demonstrated that a 1:1 inclusion complex was formed and the value of the association constant depended on the nature of the cyclodextrin. So, the association constants for the $\beta$-CD/ cinnamaldehyde and methylated $\beta-\mathrm{CD} /$ cinnamaldehyde complexes were found to be 533 and $187 \mathrm{M}^{-1}$, respectively. ${ }^{12,13}$ The dispersing effect of the $\mathrm{Pd} / \mathrm{C}$ catalyst in water was based on literature data and some experiments performed on reference solids. Indeed, Abe et al. have reported that 2,6-di-O-methyl- $\beta$-CDs can adsorb on activated carbons ${ }^{14}$ and we have demonstrated that, after several washings of $\mathrm{Pd} / \mathrm{C}$ particles by water, an important amount of cyclodextrin was always adsorbed on the $\mathrm{Pd} / \mathrm{C}$ surface. ${ }^{10}$ The consequence of $\mathrm{CD}$ adsorption on the $\mathrm{Pd} / \mathrm{C}$ surface was an increase in the hydrophilic character of the $\mathrm{Pd} / \mathrm{C}$ leading to a better dispersion of the $\mathrm{Pd} / \mathrm{C}$ particles in water.

In the presence of $\mathrm{Pd} / \mathrm{C}$, the main product is the saturated aldehyde HCAL, together with the full hydrogenated product HCOL (Figure 3a). The unsaturated alcohol COL was not observed. It is known that palladium catalyst was selective for $\mathrm{C}=\mathrm{C}$ bond hydrogenation. In the presence of 
cyclodextrins (dotted line), the performance of the catalyst increased mainly in the favour of the saturated aldehyde HCAL. Indeed, $60 \%$ yield toward HCAL was achieved after $6 \mathrm{~h}$.
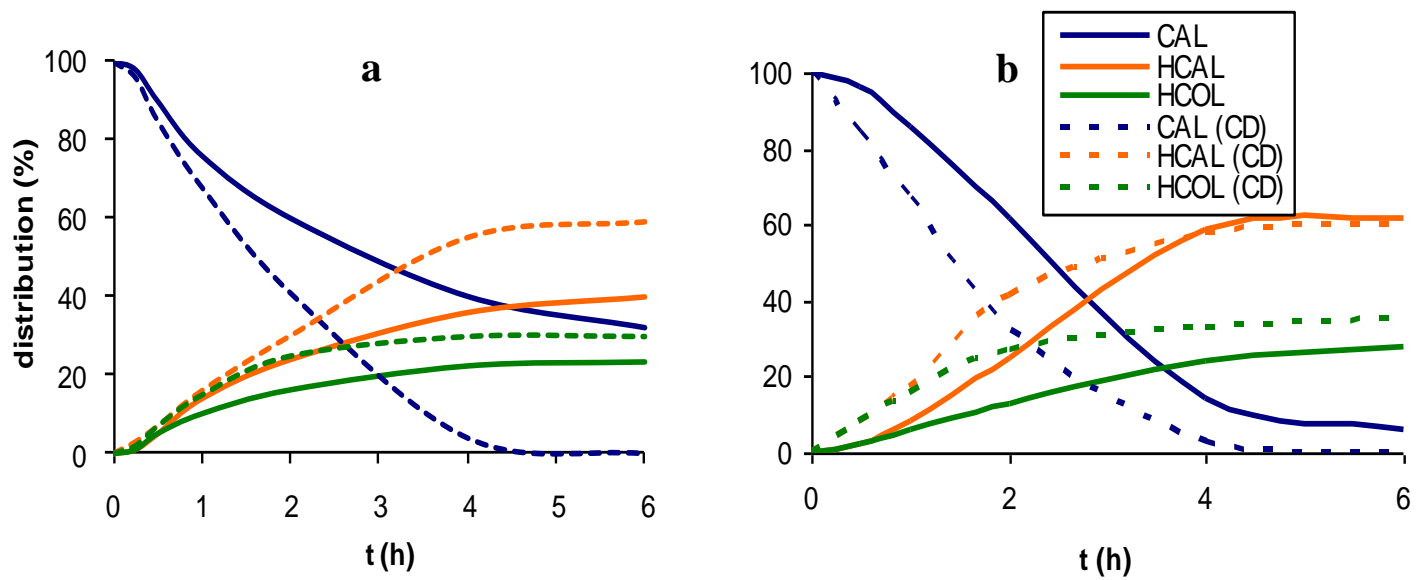

Figure 3. Influence of $\beta-C D$ in the distribution of the products for the hydrogenation of cinnamaldehyde in the presence of $\mathrm{Pd} / \mathrm{C}$ (Figure 3a) and $\mathrm{Pd} / \mathrm{SiO}_{2}$ (Figure 3b).

The influence of the support was then evaluated using $\mathrm{Pd} / \mathrm{SiO}_{2}$ catalyst (Figure $3 \mathrm{~b}$ ). In the absence of cyclodextrin, the performance of the catalyst was slightly higher compared to $\mathrm{Pd} / \mathrm{C}$ and after $4 \mathrm{~h}$, the conversion of CAL and the HCAL yield reached $86 \%$ and $65 \%$ respectively. In the presence of cyclodextrin, the reaction rate was increased but to a lesser extent. In both cases HCAL was the main product and the corresponding allylic alcohol was not observed. The reaction profile of CAL hydrogenation over $\mathrm{Pt} / \mathrm{C}$ catalyst is shown in Figure 4a.
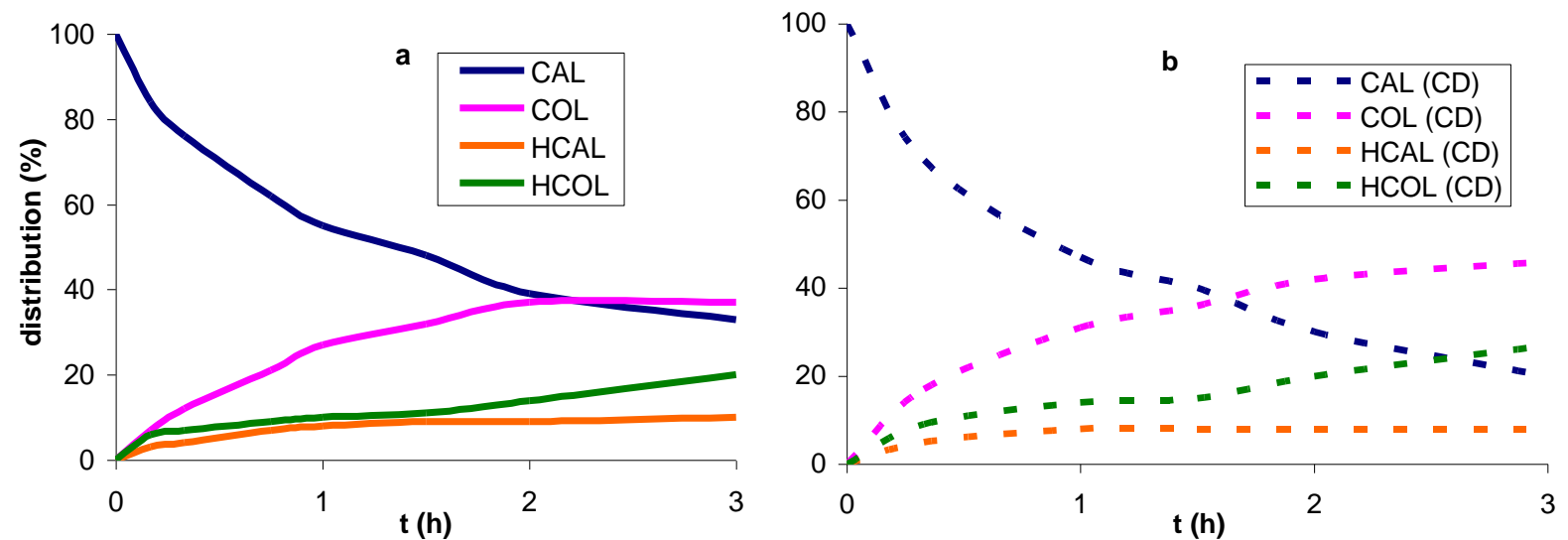

Figure 4. Hydrogenation of cinnamaldehyde in the presence of $\mathrm{Pt} / \mathrm{C}$ without (Figure $4 \mathrm{a}$ ) and with $\beta$-CD (Figure $4 b$ ). 
The reaction was performed under 10 bar $\mathrm{H}_{2}$ at room temperature. The two semihydrogenated products HCAL and COL and the fully hydrogenated compound HCOL were all formed since the beginning of the reaction. As expected, platinum catalyst hydrogenated selectively the $\mathrm{C}=\mathrm{O}$ bond and the selectivity in allylic alcohol COL reached $60 \%$.

The reaction profile achieved in the presence of $\beta-C D$ was reported in Figure $4 \mathrm{~b}$. Only a modest improvement on the performance of the Pt/C catalyst was observed after addition of $\beta$ $\mathrm{CD}$ as the conversion of CAL reached $70 \%$ with cyclodextrin after $2 \mathrm{~h}$ reaction versus $60 \%$ without CDs. Addition of cylodextrin did not modify the selectivity of the hydrogenation, the allylic alcohol COL being the main product with $60 \%$ selectivity. This moderate influence could be attributed to the partial solubility of cinnamaldehyde in water. We carried out the hydrogenation in saline solution to affect the solubility of cinnamaldehyde. In the presence of $\mathrm{NaCl}(5 \mathrm{M})$, the reaction rate was dramatically lowered and the selectivity in COL decreased to $38 \%$. No significant improvement was achieved after addition of $\beta-C D$.

The influence of several substituted cyclodextrins was then evaluated (Figure 5). Addition of cyclodextrin improved moderately the performances of the catalyst: after $2 \mathrm{~h}$, the conversion that reached $61 \%$ in absence of CDs increased to $70-79 \%$ depending on the modified cyclodextrin. The most significant enhancement was achieved using a $\beta-C D$ modified by a triazole group bearing a dimethylamino group (T- $\beta-\mathrm{CD}$, Figure 1$)$.

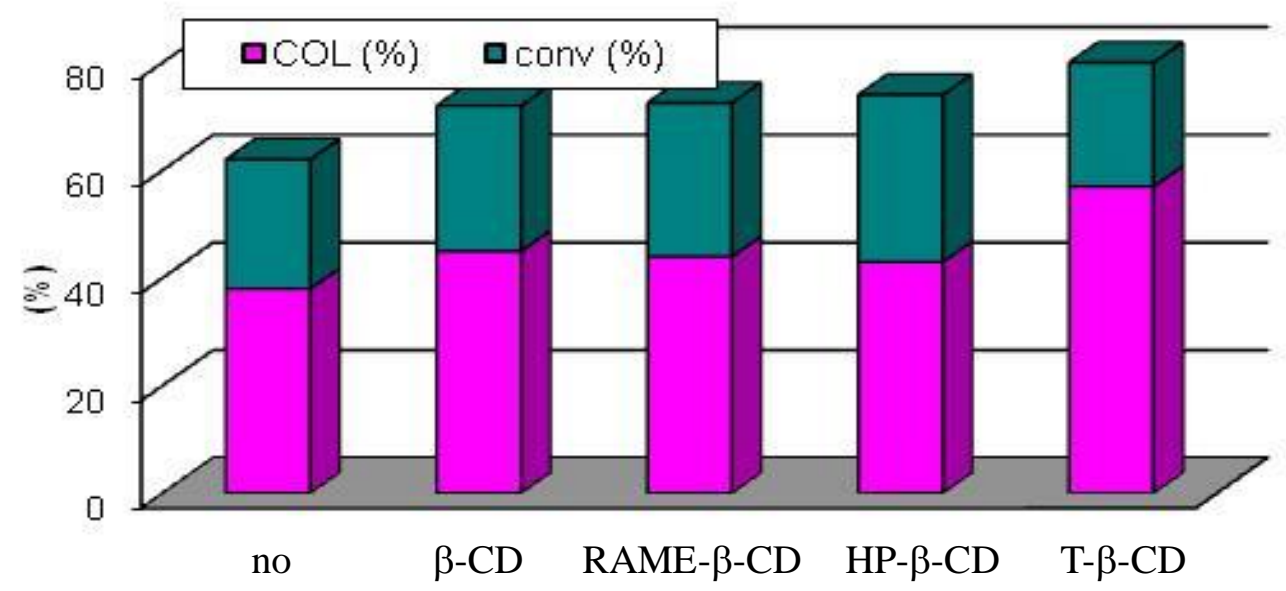

Figure 5. Hydrogenation of cinnamaldehyde with $\mathrm{Pt} / \mathrm{C}$ : influence of the presence of cyclodextrin on conversion of cinnamaldehyde and yield of COL (reaction time: $2 \mathrm{~h}$ ).

Interestingly, $\mathrm{T}-\beta-\mathrm{CD}$ influenced positively the selectivity of the hydrogenation of cinnamaldehyde (Figure 5 and Table 1 ). While addition of $\beta-\mathrm{CD}$, RAME- $\beta$-CD or HP- $\beta$-CD did not modify the selectivity toward COL that stayed around $60 \% \pm 2 \%$, the use of T- $\beta$-CD improved the selectivity towards the allylic alcohol (COL) up to $70 \%$ to the detriment of the saturated aldehyde (HCAL). 
Table 1. Influence of various cyclodextrins on the conversion and selectivity after 2 hours of reaction time

\begin{tabular}{ccccc}
\hline Cyclodextrin & Conv. (\%) & \multicolumn{3}{c}{ Selectivity (\%) } \\
& & COL & HCAL & HCOL \\
\hline- & 61 & 61 & 15 & 24 \\
$\beta-C D$ & 71 & 60 & 12 & 28 \\
RAME- $\beta-C D$ & 72 & 63 & 13 & 24 \\
HP- $\beta-C D$ & 74 & 58 & 11 & 30 \\
T- $\beta$-CD & $\mathbf{7 9}$ & $\mathbf{7 0}$ & $\mathbf{5}$ & $\mathbf{2 4}$ \\
\hline
\end{tabular}

The specific role of this substituted cyclodextrin is not clear. However, it can be suggested that T- $\beta-C D$ could also act as modifier of the metallic catalyst besides enhancing the solubility of the substrates or catalysts dispersion in water. In fact, due to the presence of triazole and dimethylamino groups, T- $\beta-C D$ could interact with platinum particles modifying the surface environment and the reactivity of the metallic catalyst (Figure 6).

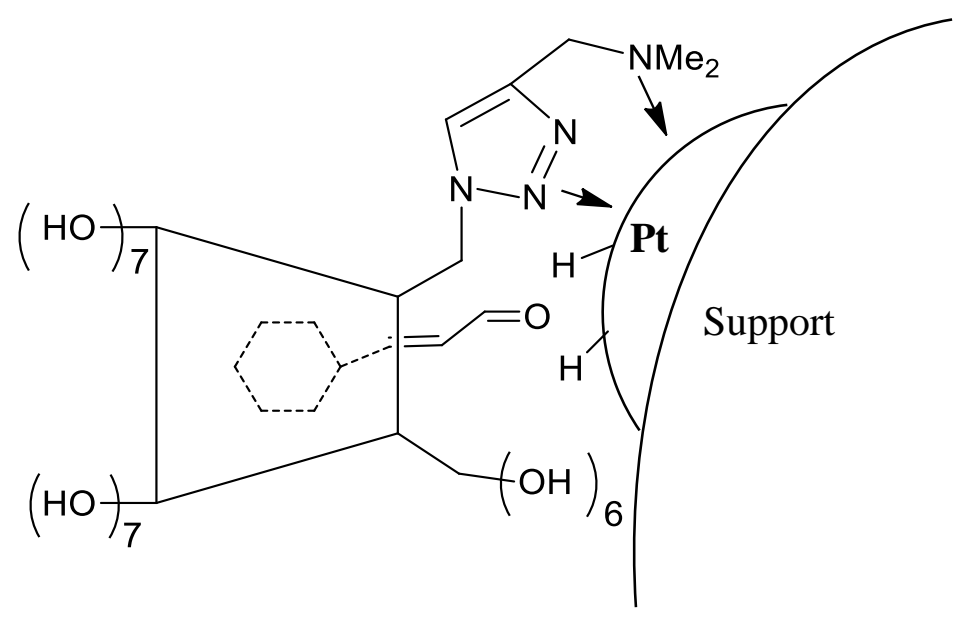

Figure 6. Schematic representation of interactions between T- $\beta-C D$, supported metallic catalyst and substrate.

\section{Conclusion}

We have shown that hydrogenation of cinnamaldehyde can be catalyzed by supported metals in water in the presence of cyclodextrin. However, to due the partial water solubility of cinnamaldehyde, the effect of cyclodextrins on the conversion and selectivity is rather modest. In fact, only a CD modified by a triazole group allowed to increase notably the COL selectivity. Works are currently under way to confirm the beneficial effect of triazole $\beta-\mathrm{CD}$ in others reactions catalyzed by supported metals. 


\section{Experimental Section}

General. $\beta-\mathrm{CD}$ and HP- $\beta-\mathrm{CD}$ were obtained from Roquettes Frères and were used as received. HP- $\beta$-CD is a mixture of $\beta$-CDs partially $O$-hydroxypropylated with statistically $4.2 \mathrm{OH}$ groups modified per CD. RAME- $\beta$-CD was purchased from Wacker Chemie GmbH and was used as received. RAMEB was of pharmaceutical grade (Cavasol ${ }^{\circledR} \mathrm{W} 7 \mathrm{M}$ Pharma). RAME- $\beta-\mathrm{CD}$ is a mixture of $\beta$-CDs partially $O$-methylated with statistically $11.8 \mathrm{OH}$ groups modified per CD. The $\mathrm{OH}$ groups in $C-6$ position are fully methylated whereas those in $C-2$ and $C-3$ positions are partially methylated. 1-(6 $6^{\mathrm{A}}$-Deoxy- $\beta$-D-cyclodextrin $)-4-[($ dimethylamino $)$ methyl $]-1,2,3$-triazole (T- $\beta$-CD) was prepared according to a published procedure. ${ }^{15}$ Commercially available $5 \% \mathrm{Pd} / \mathrm{C}$ from Aldrich (ref 20 568-0) was used as received.

Preparation of catalyst Pt/C. ${ }^{16} 15 \mathrm{~g}$ of active carbon (MAST, $1200 \mathrm{~m} 2 / \mathrm{g}$ ) were introduced in $150 \mathrm{~mL}$ water. $18 \mathrm{~mL}$ of a solution of $\mathrm{H}_{2} \mathrm{PtCl}_{6}, 6 \mathrm{H}_{2} \mathrm{O}(0.5 \% \mathrm{Pt})$ was added dropwise and the solution was stirred at room temperature overnight. The suspension was cooled down to $0^{\circ} \mathrm{C}$ with ice bath and $75 \mathrm{~mL} \mathrm{HCHO} \mathrm{(37 \% )} \mathrm{were} \mathrm{added} \mathrm{over} 20$ min followed by $30 \mathrm{~mL} \mathrm{KOH} \mathrm{(30 \% ).}$ The suspension was stirred overnight. The solid was filtered and washed with water until neutrality. The catalyst was the dried at $120^{\circ} \mathrm{C}$ for $12 \mathrm{~h}$. The platinum loading measured by elemental analysis was $4.4 \%$.

Preparation of catalyst Pd/SiO2. ${ }^{17}$ Silica Aerosil 200 was added in water $\left(100 \mathrm{~mL} / \mathrm{g} \mathrm{SiO}_{2}\right)$ in a round bottle flask under vigorous stirring. After $2 \mathrm{~h}$ water was evaporated. The silica was then dried in air at $120{ }^{\circ} \mathrm{C}$, then slightly crushed and sifted. For the following experiment, we selected the particle sizes 40-60 mesh $(250-400 \mathrm{~nm})$ that allow easy handling of the material.

A solution of $\mathrm{Pd}(\mathrm{acac})_{2}$ in toluene (made from $2.8 \mathrm{~g}$ of $\mathrm{Pd}(\mathrm{acac})_{2}$ in $40 \mathrm{ml}$ of toluene) was added to $10 \mathrm{~g}$ of agglomerated silica. The mixture was then stirred for $1 \mathrm{~h}$ at room temperature (r.t.) under argon, before the toluene is evaporated to give a slightly yellow material. This was calcinated under air flow $(100 \mathrm{~mL} / \mathrm{min})$ at $300{ }^{\circ} \mathrm{C}$ for $5 \mathrm{~h}$ to give $\mathrm{PdO} / \mathrm{SiO}_{2}$ as a brown material. Subsequent reduction under $\mathrm{H}_{2}$ flow $(120 \mathrm{~mL} / \mathrm{min})$ at $300^{\circ} \mathrm{C}$ for $3 \mathrm{~h}$ gave the $\mathrm{Pd} / \mathrm{SiO}_{2}$ catalysts as a black material. AAS determination gave $8.7 \pm 0.1 \%$ wt $\mathrm{Pd}$.

\section{Catalytic tests}

With Palladium catalyst. The reaction was carried out in Schlenck vessel connected to hydrogen reservoir. Cinnamaldehyde was introduced in water together with catalyst and optionally cyclodextrin. The reactor was purged three times with $\mathrm{N} 2$ atmosphere, once with $\mathrm{H} 2$ and the reaction mixture was stirred. Samples were periodically withdrawn for analysis. The sample $(0.5 \mathrm{~mL})$ was extracted with $1.5 \mathrm{~mL}$ AcOEt, the organic layer was dried over MgSO4 and analyzed by gas chromatography (Shimadzu GC 14B) using an capillary column (DB-5, 30 $\mathrm{m} \times 0.32 \mathrm{~mm} \times 0.25 \mu \mathrm{m})$. 
With Platinum catalyst. The liquid-phase hydrogenation of cinnamaldehyde was carried out in a 20-ml stainless steel reactor equipped with a Teflon-pot. $132 \mathrm{mg}$ of cinnamaldehyde and cyclodextrin (if mentioned) were introduced in $10 \mathrm{~mL}$ water and the mixture was submitted to ultrasonic bath for 5 min to obtain a well dispersed emulsion. The catalyst was then added and the Teflon-pot was charged in the autoclave that was purged with argon. The reaction was performed under 10 bar $\mathrm{H}_{2}$ and samples were periodically withdrawn for analysis.

\section{Acknowledgements}

Roquette Frères (Lestrem, France) is gratefully acknowledged for generous gifts of cyclodextrins. The authors gratefully acknowledge the National Agency of Research (CATAQ $\mathrm{N}^{\circ}$ ANR-07-CP2D-0167-01/02) for funding. MJ thanks NAR for a grant.

\section{References}

1. Gallezot, P.; Richard, D. Catal. Rev. Sci. Eng. 1998, 40, 81.

2. Bachiller-Baeza, B.; Rodriguez-Ramos, I.; Guerrero-Ruiz, A. Applied Catal. A 2001, 205 , 227.

3. (a) Fukuoka, A.; Kosugi, W.; Morihita, F.; Hirano, M.; McCaffrey, L.; Henderson, W. Chem. Commun. 1999, 489. (b) Joo, F.; Kovacs, J.; Benyei, A.; Katho, A.; Catal. Today 1998, 42, 441.

4. P.N. Rylander, in Catalytic Hydrogenation in Organic Synthesis, Academic Press, NewYork, 1979, p 72.

5. (a) da Silva, A.B.; Jordao, E.; Mendes, M.J.; Fouilloux, P. Applied Catal. A 1997, 148, 253.

(b) P. Vu, H; Goncalves, F.; Philippe, R.; Lamouroux, E.; Corrias, M. ; Kihn, Y.; Plee, D.; Kalck, P.; Serp, P. J. Catal. 2006, 240, 18.

6. (a) Szöllösi, G.; Török, B.; Baranyi, L.; Bartok, J. Catal. 1998, 179, 619. (b) Steffan, M.; Klasovsky, F.; Arras, J.; Roth, C.; Radnik, J.; Hofmeister, H.; Claus, P. Adv. Synth. Catal. 2008, 350, 1337. (c) Cabiac, A.; Cacciaguerra, T.; Trens, P.; Durand, R.; Delahaye, G.; Medebielle, A.; Plée, D.; Coq, B. Applied Catal. A 2008, 340, 229.

7. (a) Gallezot, P.; Giroir-Fendler, A.; Richard, D. Catal. Lett. 1990, 4, 169. (b) Hajek, J.; Kumar, N.; Maki-Arvela, P.; Salmi, T.; Murzin, D.Y.; Paseda, I.; Heikkila, T.; Laine, E.; Laukkanen, P.; Vayrynen, J. Applied Catal. A 2003, 251, 385.

8. (a) Toebes, M.L.; Zhang, Y.; Hajek, J.; Nijhuis, T.A.; Bitter, J.H.; van Dillen, A.J.; Murzin, D.Y., Koningsberger, D.C.; de Jong, K.P. J. Catal. 2004, 226, 215. (b) Plomp, A.J.; Vuori, H.; Krause, A.O.I., de Jong, K.P.; Bitter, J.H. Applied Catal. A 2008, 351, 9. (c) Tessonier, J.P.; Pesant, L.; Ehret, G.; Ledoux, M.J.; Pham-Huu, C. Applied Catal. A 2005, 288, 203. 
9. (a) Hapiot, F.; Tilloy, S.; Monflier, E. Chem. Rev. 2006, 106, 767. (b) Bricout, H.; Hapiot, F.; Ponchel, A.; Tilloy, S.; Monflier, E. Curr. Org. Chem 2010, 14, 1296. (c) Hapiot, F.; Ponchel, A.; Tilloy, S.; Monflier, E. C. R. Chimie 2011, 14, 149.

10. (a) Cassez, A.; Kania, N.; Hapiot, F.; Fourmentin, S.; Monflier, E.; Ponchel, A. Catal. Commun. 2008, 9, 1346. (b) Cassez, A.; Ponchel, A.; Hapiot, F.; Monflier E. Org. Lett. 2006, 8, 4823.

11. Chen, H.; Ji, H.; Zhou, X.; Wang, L. Tetrahedron 2010, 66, 9888.

12. Zhang, Q.F.; Jiang, Z.T.; Zhao, Q.; Yang, L.; Shao, C. Shipin Yu Fujiao Gogye 2006, 32(8), 68.

13. He, J.; Li, W. J. Incl. Phenom. Macrocycl. Chem. 2009, 63, 61.

14. Abe, I.; Kukuhara, T.; Kawasaki, N.; Hitomi, M.; Kera, Y. J. Colloid Interf. Sci. 2000, 229, 615.

15. Mourer, M.; Hapiot, F.; Tilloy, S.; Monflier, E.; Menuel, S. Eur. J. Org. Chem. 2008, 5723.

16. Donze, C.; Korovchenko, P.; Gallezot, P.; Besson, M. Applied Catal. B 2007, 70, 621.

17. (a) Joucla, L.; Cusati, G.; Pinel, C.; Djakovitch, L. Adv. Synth. Catal. 2010, 352, 1993. (b) Tarabay, J.; Al-Maksoud, W.; Jaber, F.; Pinel, C.; Prakash, S.; Djakovitch, L. Appl. Catal. A: Gen. 2010, 388, 124. 